\title{
Impact of environmental factors on the spread of dengue fever in Sri Lanka
}

\author{
M. O. Faruk ${ }^{1}$ (i) S. N. Jannat ${ }^{1} \cdot$ Md. S. Rahman ${ }^{2}$
}

Received: 27 July 2021 / Revised: 11 December 2021 / Accepted: 30 December 2021 / Published online: 14 January 2022

C) Islamic Azad University (IAU) 2022

\begin{abstract}
Dengue fever is a mosquito-borne viral disease caused by the dengue virus of the Flaviviridae family and is responsible for colossal health and economic burden worldwide. This study aimed to investigate the effect of environmental, seasonal, and spatial variations on the spread of dengue fever in Sri Lanka. The study used secondary data of monthly dengue infection and the monthly average of environmental parameters of 26 Sri Lankan regions from January 2015 to December 2019. Besides the descriptive measurements, Kendall's tau_ $b$, Spearman's rho, and Kruskal-Wallis $H$ test have been performed as bivariate analyses. The multivariate generalized linear negative binomial regression model was applied to determine the impacts of meteorological factors on dengue transmission. The aggregate negative binomial regression model disclosed that precipitation (odds ratio: 0.97, $p<0.05$ ), humidity (odds ratio: $1.05, p<0.01$ ), and air pressure (odds ratio: $1.46, p<0.01$ ) were significantly influenced the spread of dengue fever in Sri Lanka. The bioclimatic zone is the vital factor that substantially affects the dengue infection, and the wet zone (odds ratio: 6.41, $p<0.05$ ) was more at-risk than the dry zone. The climate season significantly influenced dengue fever transmission, and a higher infection rate was found (odds ratio: $1.46, p<0.01$ ) in the northeast monsoon season. The findings of this study facilitate policymakers to improve the existing dengue control strategies focusing on the meteorological condition in the local as well as global perspectives.
\end{abstract}

Keywords Aedes mosquito $\cdot$ Dengue fever $\cdot$ Meteorological factors $\cdot$ Negative binomial regression $\cdot$ Spatio-temporal analysis $\cdot$ Vector-borne disease

\section{Introduction}

Dengue fever is an arthropod vector-borne viral infection transmitted primarily by Aedes aegypti and secondarily by Aedes albopictus mosquitoes. It has a higher infection rate in tropical and subtropical areas and poses a global threat for around four billion inhabitants of more than 141 countries. It has been estimated that approximately 390 million dengue cases with 25,000 deaths have occurred worldwide annually (Brady et al. 2014; World mosquito program 2021). Threequarters of the dengue cases come from the South-East Asia

\section{Editorial responsibility: Chenxi Li.}

M. O. Faruk

omarfaruk.faruk396@gmail.com

1 Department of Statistics, Noakhali Science and Technology University, Noakhali, Chittagong 3814, Bangladesh

2 One Health Center for Research and Action, Akbarshah, Chattogram 4207, Bangladesh and Western Pacific regions of WHO (Bhatt et al. 2013). In Sri Lanka, the first dengue case was confirmed in 1962, while the first outbreak had recorded in 1965 (Sirisena and Noordeen 2014). The dengue virus has four serotypes DENV 1, 2, 3, and 4. However, one new serotype, DENV 5, was identified in Malaysia in 2007 (Mustafa et al. 2015). All four dengue virus serotypes have been co-circulating in Sri Lanka for more than 35 years (Sirisena and Noordeen 2014). The country experienced its worst-ever dengue outbreak in 2017 , with more than 175,000 cases and nearly 400 fatalities (Daily News 2017). A model predicted that the dengue infection will increase up to 2.25 billion worldwide by 2080 (Messina et al. 2019).

Climate plays a significant role in the spared of dengue through impacting the mosquito life cycle (Liyanage et al. 2016a). Mosquitoes are known as ectotherms, i.e., their breeding and activity depend mainly on the surrounding environment (Blanford et al. 2013). An entomological study showed that Aedes mosquitoes primarily breed in different containers with stagnant clean and organically 
rich water like plastic buckets, tier, coconut shells, etc. (Sirisena and Noordeen 2014; Rahman et al. 2021b). Precipitation plays a crucial role as water is required to hatch mosquito eggs and develop the larval stage (Wagner et al. 2020). Larvae live in water, and their development takes about 7-10 days. The dengue virus transmission creates a complex interrelation with local meteorological factors. Rainfall and temperature play a crucial role in dengue fever transmission (Naish et al. 2014). The transmission of the viruses occurs between 18 and $34{ }^{\circ} \mathrm{C}$ and peaks in the range of $26-29{ }^{\circ} \mathrm{C}$ (Mordecai et al. 2017). However, previous studies in different countries showed a range of combinations of various surrounding environmental parameters on dengue transmission (Choi et al. 2016; Johansson et al. 2016; Rahman et al. 2021a). The literature also stated that temperature, rainfall, relative humidity, and population density were associated with dengue infection in high-risk areas (Zhu et al. 2016; Sharmin et al. 2018). Investigations revealed that dengue fever incidence in Sri Lanka was caused by the factors: precipitation, wind, urbanization, land management, socio-demographic characteristics, etc. (Sirisena et al. 2017; Wagner et al. 2020). Rainfall positively impacts dengue incidence in Sri Lanka (Liyanage et al. 2016a; Sirisena et al. 2017). The country's two annual peaks of dengue incidence are correlated with the two monsoons season during May to September and December to February (Liyanage et al. 2016a, Prabodanie et al. 2020b). Consequently, western provinces possessed higher dengue cases (41\% in 2017) than the eastern parts of the country (7\% during the 2017 outbreak) (Lazarus 2021). Sri Lanka provides a compelling location for studying the effect of climate on dengue transmission due to highly varied rainfall patterns in the island (Prabodanie et al. 2020b). Moreover, dengue fever shared a few common clinical signs with COVID-19 infection which has created misdiagnosis and delay diagnosis during the pandemic (Rahman and Rahman 2020). The COVID-19 associated circumstances also hampered the usual surveillance and other programs of different diseases including dengue. Therefore, this study excluded the data of the year 2020.

Due to the climate-sensitive nature of dengue, a common control strategy may not work effectively throughout the country. Hence, dengue monitoring and prevention efforts should focus on the local scale (Ooi et al. 2006). This study attempted to understand the potential effect of various environmental, seasonal, and spatial factors on dengue infection in Sri Lanka. Monthly dengue data along with climate and weather indicators of 26 cities from January 2015 to December 2019 have been used in this research. The results will support concerned personnel to reduce the regional-based transmission risk and help prevent the spread of dengue infection.

\section{Materials and methods}

\section{Study area}

Sri Lanka is a tropical island of the Indian Ocean located within the tropics between $5^{\circ} 55^{\prime} \mathrm{N}$ and $9^{\circ} 51^{\prime}$ North latitudes and between $79^{\circ} 42^{\prime}$ and $81^{\circ} 53^{\prime}$ East longitude. The island is divided into four climatic zones based on the yearly climate: wet, intermediate, dry, and arid. The wet zone receives rainfall in all seasons, and the average annual rainfall varies from 2000 to $5000 \mathrm{~mm}$. Intermediate, dry, and arid zones receive $1100-2000 \mathrm{~mm}, 700-1000 \mathrm{~mm}$, and less than $700 \mathrm{~mm}$ annual rainfall, respectively (Prabodanie et al. 2020b). In this study, the aird zone has been merged with the dry zone and considered the country into three distinct zones. The different climatic zones in Sri Lanka are presented in Fig. 1a. The monsoon winds of the Bay of Bengal and the Indian Ocean influence the pattern of precipitation which marks the climate seasons in the study area (Asian Disaster Reduction Center 2020). The spatial distribution of precipitation in different climate seasons in Sri Lanka is illustrated in Fig. 1b-e. The climate of Sri Lanka can be characterized into 4 seasons based on 12 months period that it inveterate: (1) The first inter-monsoon (FIM) season (March-April): this term is uncomfortable with thunderstorm-type rain, mainly throughout the afternoon or evening. The amount of rainfall varies between 100 and $250 \mathrm{~mm}$ in most parts of the island (Fig. 1b).

(2) Southwest monsoon (SWM) season (May-September): This term brings windy weather that eases off the hotness of the 1st inter-monsoon season, and the rainfall varies from about $100 \mathrm{~mm}$ to over $3000 \mathrm{~mm}$ in Sri Lanka. Relatively active southwest monsoon causes heavy rain and warm, humid air to the western part of the country (Fig. 1c). (3) Second intermonsoon (SIM) season (October-November): In the second inter-monsoon season, thunderstorm-type rain and cyclones are common in the Bay of Bengal. Widespread rain with strong winds leads to floods and landslides on the island. The whole country receives $400 \mathrm{~mm}$ or more rain, and higher rainfall (750-1200 mm) occurs in Southwestern slops during this season (Fig. 1d). (4) Northeast monsoon (NEM) season (December-February): This season comprises relatively cool but dry weather that makes immediate comfortable and pleasant conditions over most parts of Sri Lanka. The days remain full of sunshine, and nights are cool with a cloud-free sky. Unless this pleasant weather, some parts of the country experience rain during this season (Fig. 1e) (Climate of Sri Lanka 2021).

\section{Data collection}

This study used secondary data of monthly dengue infections and different environmental parameters of 26 regions of Sri Lanka from January 2015 to December 2019. The key 


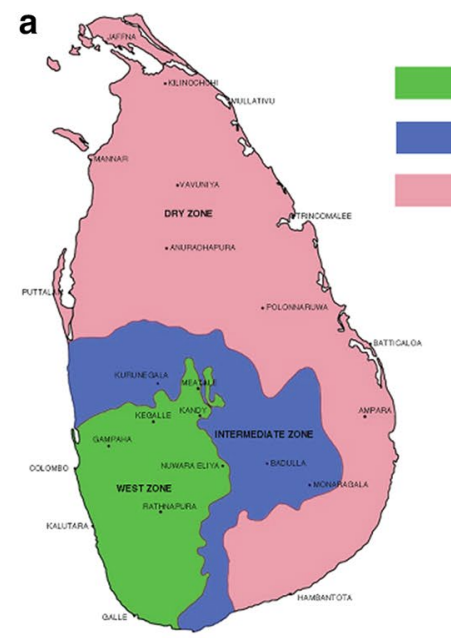

Wet Zone $=>$ Annual Rainfall 2000

Intermediate Zone $=$ Annual Rainfall $1150-2000$

Dry Zone $=<$ Annual Rainfall 1100

(Source: Punyawardena, 2017)
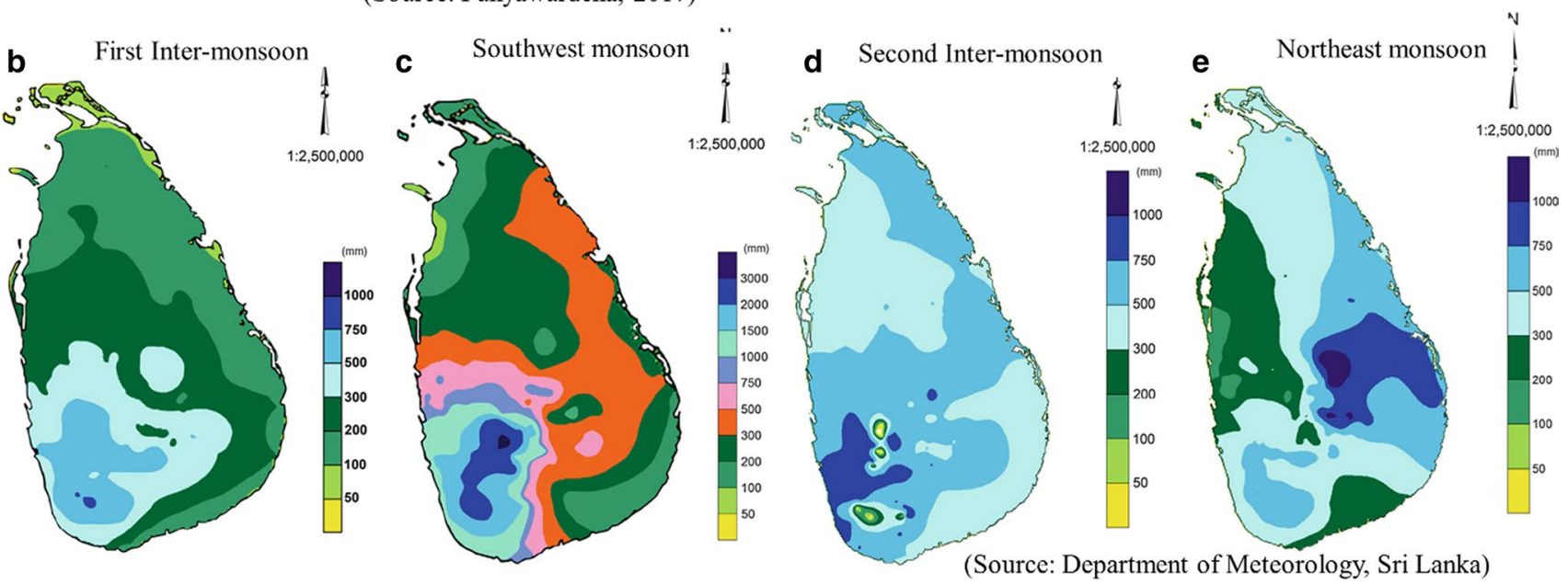

Fig. 1 Spatial distribution of climatic zones and average precipitation in different climate seasons in Sri Lanka

environmental factors considered in this study were temperature, relative humidity, precipitation, sky clearness, air pressure, and wind speed. In addition to these ecological factors, this study also included bioclimatic zone and climate season as exogenous variables suspected to influence the study variable significantly. Based on the annual rainfall, the country is divided into 3 bioclimatic zones in this study. From 26 regions, 13 regions belong to the dry zone, 6 to the intermediate zone, and 7 to the wet zone. The dengue infection data were collected from the Health Ministry of Sri Lanka (Epidemiology Unit of Ministry of Health 2019). The monthly dengue infection raw data for every year extracted from the website were organized in an excel sheet. Regions, months, and dengue cases were arranged in the first three columns in the excel sheet. The meteorological data were extracted from the NASA Power Data Access Viewer (NASA Power 2021). The environmental parameters were measured in different units: precipitation in millimeter $(\mathrm{mm})$, relative humidity in percentage (\%), air pressure in kilo Pascale $(\mathrm{kPa})$, the temperature in degree Celsius $\left({ }^{\circ} \mathrm{C}\right)$, wind speed in meter per second $(\mathrm{m} / \mathrm{s})$, whereas sky clearness was unitless. Generally, sky clearness is a dimensionless number between 0 and 1 . It is defined as the ratio of radiation and extraterrestrial radiation (HOMER). The monthly averages of environmental factors were collected and systematically organized in each row corresponding to the individual region and months. The 4th and following columns were featured by the environmental factors, respectively. Eventually, the bioclimatic zone and climate season were included in the subsequent columns. This approach had been followed for each of the individual years. Finally, all 5-year data were merged into a single data file for the aggregate regression model.

\section{Data analysis}

The focal outcome variable considered in this analysis was the number of monthly dengue infections. Descriptive statistics for the chosen environmental variables were mean, 
standard deviation (SD), maximum, minimum, skewness, and kurtosis. The $95 \%$ confidence interval indicates the impact size for the number of dengue cases in 26 cities of Sri Lanka. As the study variable considered here was a count variable, several statistical approaches were applied to find the appropriate statistical analysis. For testing the linearity of the variables, analysis of variance (ANOVA) tables was computed for each of the explanatory variables concerning the dependent variable. The $p$ values corresponding to the deviation from linearity in the ANVOA table were observed, confirming the non-linear relationships $(p<0.05)$ between independent and dependent variables. Besides the linearity test, the one-sample Kolmogorov-Smirnov normality test was applied to the data and found no evidence of normality $(p<0.05)$. Since the variables considered in this study did not follow linearity and normality assumptions, it would be apposite to use the non-parametric statistical methods. To assess the bivariate relationship between the spread of dengue infections and various environmental variables, Kendall's tau_ $b$ and Spearman's rho correlation coefficients were computed. The meteorological variables which found significant in bivariate analysis were also considered in multivariate analysis. In addition to the climate variables, spatial and cyclical or seasonal variables were also included in the multivariate model. Kruskal-Wallis $H$ test was applied as bivariate analysis to test the significant mean difference of Aedes infections among the spatial, temporal, and seasonal variable categories. The multivariate generalized linear model (GLM) was employed to determine the factors that significantly influence the spread of dengue disease in Sri Lanka. Since the study variable was a count variable, the Poisson regression (PR) model and the negative binomial regression (NBR) model with the log link function were used as non-parametric regression analysis.

Akaike information criteria (AIC) values were calculated for each model, and the best was chosen for the study. The AIC value for the NBR model was found least than that of the PR model. Hence, it can be said that the NBR model is better than the PR model. Firstly, the NBR model was applied for each individual year from 2015 to 2019 . Secondly, it was also employed for the aggregate dataset
(2015-2019) as a whole. Augmented Dicky-Fuller (ADF) test was performed to test the possible existence of unit root in the aggregate dataset. The ADF test provides the evidence of no unit root, i.e., the dataset was stationary, indicating no restrictions to apply the usual statistical approach. Moreover, the Chi-square test statistic was calculated based on the NBR and PR model's loglikelihood deviation. The Chi-square test proved the evidence of overdispersion of the data. Hence, the NBR model had been consciously applied for the analysis as it is appropriate for the overdispersed count data. All the descriptive and bivariate analyses were performed on the IBM SPSS (Statistical Package for the Social Science) version 25 , and multivariate GLM was conducted in R version 4.1.1.

\section{Results and discussion}

A descriptive analysis was performed for both study and explanatory variables before analyzing relationships between environmental factors and dengue fever. Table 1 represents the descriptive measures of various ecological parameters within the period of 2015-2019. The highest average precipitation was observed $7.28 \mathrm{~mm}$ in 2018. In contrast, the minimum value was recorded $3.67 \mathrm{~mm}$ in 2016. The 5 -year average precipitation was $5.28 \mathrm{~mm}$, and the average humidity level was $80.60 \%$. In the study period, the maximum and minimum average humidity was recorded at $83.43 \%$ (2015) and $78.38 \%$ (2019), respectively, and it has a negatively skewed distribution. The mean air pressure was 99.42 (SD: $1.78) \mathrm{kPa}$, and it was found to have close to the mean value for all five individual years.

The 5-year mean temperature was $27.29^{\circ} \mathrm{C}$ which ranges from $26.86^{\circ} \mathrm{C}$ (2015) to $27.71{ }^{\circ} \mathrm{C}$ (2019). The highest average wind speed $(4.27 \mathrm{~m} / \mathrm{s})$ was recorded in 2019 and the lowest $(1.03 \mathrm{~m} / \mathrm{s})$ in 2015 . The average sky clearness was 0.65 for the whole study period. The lowest value of sky clearness $(0.50)$ was observed in 2019 . The total number of dengue infections in different cities throughout 2019 is presented in Fig. 2 to observe the distribution of dengue infections in various Sri Lankan locations.

Table 1 Descriptive statistics of the selected environmental factors in Sri Lanka (2015-2019)

\begin{tabular}{|c|c|c|c|c|c|c|c|c|c|c|c|}
\hline \multirow[t]{2}{*}{ Environmental factors } & \multirow[t]{2}{*}{ Mean (2015) } & \multirow[t]{2}{*}{ Mean (2016) } & \multirow[t]{2}{*}{ Mean (2017) } & \multirow[t]{2}{*}{ Mean (2018) } & \multirow[t]{2}{*}{ Mean (2019) } & \multicolumn{6}{|c|}{ 2015-2019 } \\
\hline & & & & & & Mean & SD & Min & $\operatorname{Max}$ & Skew & Kurt \\
\hline Precipitation (mm) & 5.11 & 3.67 & 4.23 & 7.28 & 5.12 & 4.72 & 3.99 & 0.03 & 19.06 & 1.18 & 0.79 \\
\hline Humidity (\%) & 83.43 & 79.52 & 79.35 & 82.34 & 78.38 & 80.60 & 6.07 & 60.63 & 100.00 & -0.25 & 0.54 \\
\hline Air pressure $(\mathrm{kPa})$ & 99.49 & 99.43 & 99.40 & 99.41 & 99.35 & 99.42 & 1.78 & 93.39 & 101.33 & -1.47 & 1.66 \\
\hline Temperature $\left({ }^{\circ} \mathrm{C}\right)$ & 26.86 & 27.57 & 27.39 & 26.94 & 27.71 & 27.29 & 2.02 & 20.90 & 33.14 & -0.31 & -0.11 \\
\hline Wind speed $(\mathrm{m} / \mathrm{s})$ & 1.03 & 1.72 & 1.17 & 1.19 & 4.27 & 1.88 & 2.08 & 0.01 & 8.86 & 1.14 & 0.29 \\
\hline Sky clearness & 0.69 & 0.68 & 0.68 & 0.68 & 0.50 & 0.65 & 0.08 & 0.37 & 0.71 & -1.88 & 2.37 \\
\hline
\end{tabular}


From Fig. 2, it is observed that the two most infected cities were Colombo $(n=20,718)$ and Gampaha $(n=16,573)$, which are located under the wet zone, and the lowest infection was found in Mannar $(n=271)$ and Mullaitivu $(n=268)$, located in dry areas of Sri Lanka.

A temporal and spatial comparison of the total number of Aedes infections is illustrated in Fig. 3a. The figure shows that the number of Aedes infections had an upward trend from 2015 to 2017 but dramatically fell in 2018 . The maximum number of diseases was recorded in the wet zone in 2017 , followed by the intermediate zone in the same year. The dry area had minimum conditions in 2015-2017 and observed the second most infected zone in 2018 and 2019. From Fig. 3a, it is observed that the wet zone had a maximum number of infections in all 5 years. To better understand the cyclical or seasonal impact on the Aedes infection transmission, this study also compares the seasonal variability of total contagions for the individual years, presented in Fig. 3b. The maximum number of Aedes infections was found in the southwest monsoon season in 2017, and the high illness was observed for the next 2 years in the same season.
The minimum number of Aedes infections was observed in the first inter-monsoon season for each of the years. A moderate number of diseases were found for both northeastmonsoon and second inter-monsoon seasons.

Besides the descriptive measures of environmental factors, we also calculated the descriptive statistics of the number of dengue infections in different regions of Sri Lanka in 2019 and presented in Table 2. It revealed that the maximum monthly mean of disease was found in Colombo $(1726.59 \pm 1122.81)$ followed by Gampaha $(1381.08 \pm 912.74)$, and the minimum mean infection was in Mannar $(22.58 \pm 35.90)$ followed by Moneragala $(27.75 \pm 24.26)$.

The distribution of disease was highly positively skewed $\left(\gamma_{1}=2.87\right.$ and 2.83) and leptokurtic $\left(\gamma_{2}=8.53\right.$ and 8.69) for Trincomalee and Mannar cities, respectively. In contrast, the distribution was negatively skewed $\left(\gamma_{1}=-0.09\right.$ and -0.04$)$ and platykurtic $\left(\gamma_{2}=-1.74\right.$ and -1.81$)$ for the cities Galle and Moneragala, respectively.

In addition to the descriptive statistics, the correlation coefficient of the dengue infections and different environmental factors was also measured and presented in Table 3 .
Fig. 2 Total number of dengue cases recorded in different cities of Sri Lanka in 2019

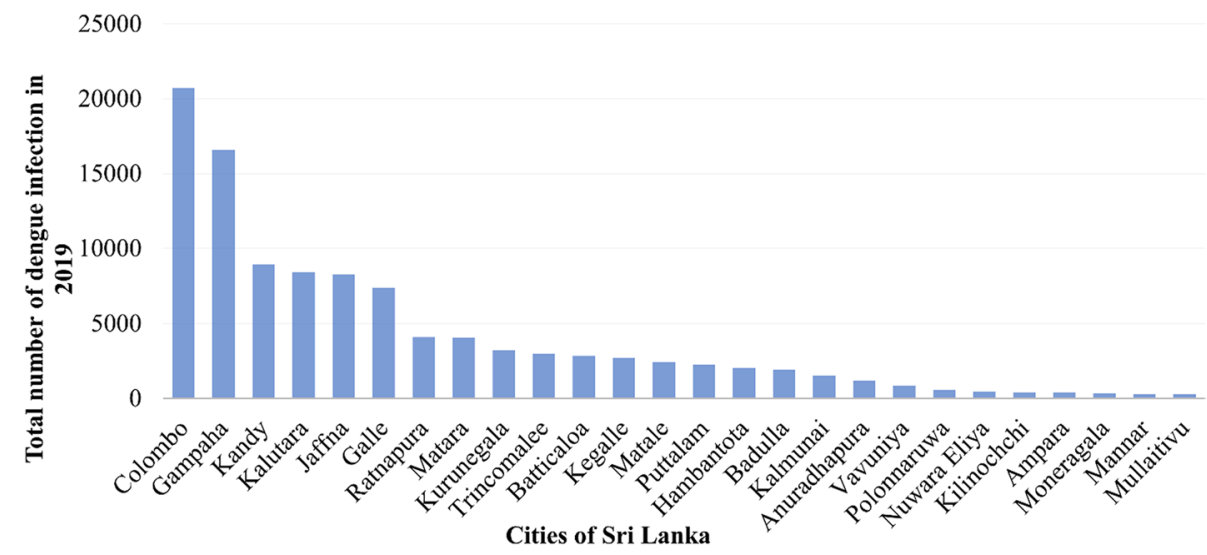

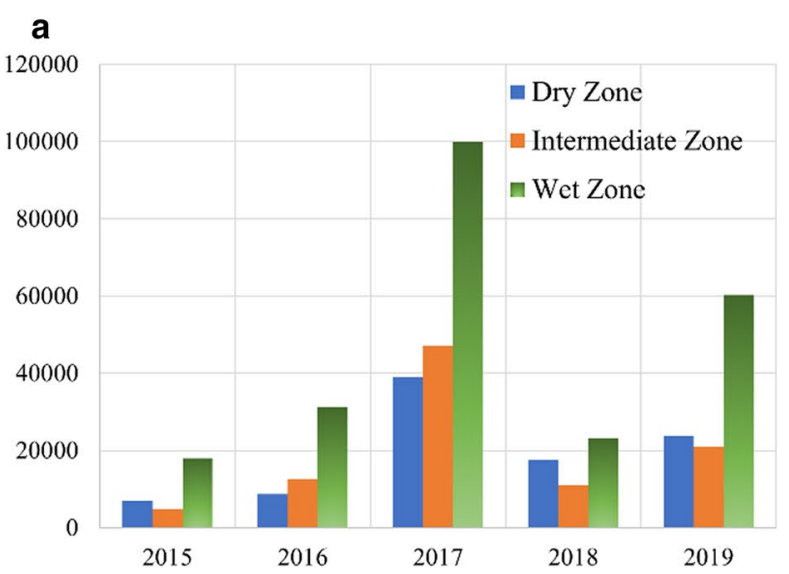

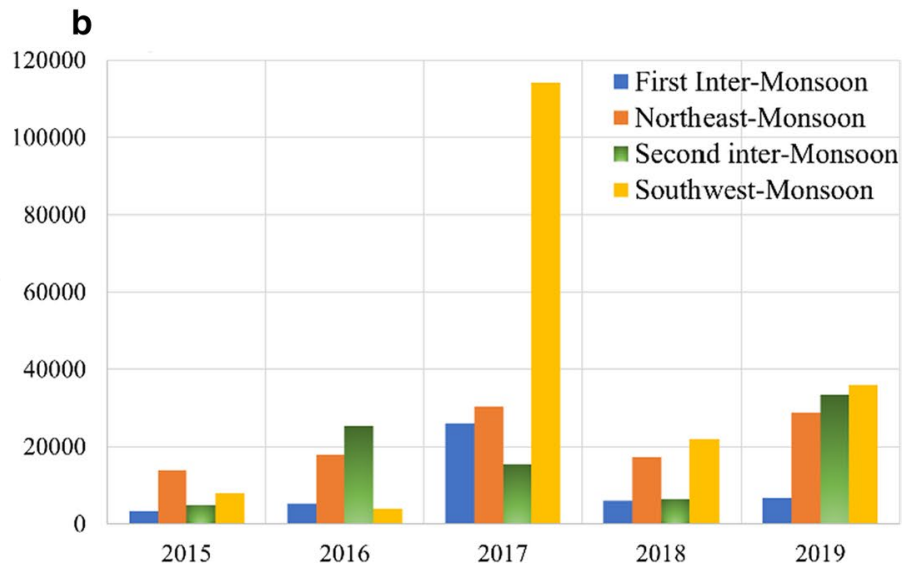

Fig. 3 Temporal comparison of the total number of Aedes infections in different climatic zones and seasons in Sri Lanka 
Table 2 Descriptive measures of the number of dengue infections in different regions of Sri Lanka in 2019

\begin{tabular}{|c|c|c|c|c|c|c|c|c|}
\hline \multirow[t]{2}{*}{ Cities } & \multirow[t]{2}{*}{ Mean (monthly) } & \multirow[t]{2}{*}{ Standard deviation } & \multirow[t]{2}{*}{ Minimum } & \multirow[t]{2}{*}{ Maximum } & \multirow[t]{2}{*}{ Skewness } & \multirow[t]{2}{*}{ Kurtosis } & \multicolumn{2}{|c|}{$\begin{array}{l}95 \% \text { confidence interval for } \\
\text { mean }\end{array}$} \\
\hline & & & & & & & Lower bound & Upper bound \\
\hline Colombo & 1726.50 & 1122.81 & 579 & 4217 & 1.22 & 0.81 & 1013.10 & 2439.90 \\
\hline Gampaha & 1381.08 & 912.74 & 429 & 3154 & 0.60 & -0.79 & 801.16 & 1961.01 \\
\hline Kalutara & 699.58 & 399.80 & 202 & 1310 & 0.04 & -1.64 & 445.56 & 953.60 \\
\hline Kandy & 745.00 & 709.22 & 192 & 2444 & 1.54 & 1.78 & 294.39 & 1195.61 \\
\hline Matale & 203.75 & 309.67 & 17 & 902 & 1.90 & 2.27 & 6.99 & 400.51 \\
\hline Nuwara Eliya & 36.50 & 29.08 & 7 & 97 & 1.42 & 1.05 & 18.02 & 54.98 \\
\hline Galle & 614.83 & 392.20 & 123 & 1155 & -0.09 & -1.74 & 365.64 & 864.03 \\
\hline Hambantota & 170.75 & 75.46 & 80 & 272 & 0.17 & -1.70 & 122.81 & 218.69 \\
\hline Matara & 337.83 & 209.69 & 101 & 717 & 0.43 & -1.06 & 204.60 & 471.07 \\
\hline Jaffna & 688.42 & 971.78 & 59 & 2763 & 1.80 & 1.93 & 70.98 & 1305.85 \\
\hline Kilinochchi & 33.00 & 42.32 & 5 & 141 & 2.11 & 3.68 & 6.11 & 59.89 \\
\hline Mannar & 22.58 & 35.90 & 1 & 130 & 2.83 & 8.69 & -0.23 & 45.39 \\
\hline Vavuniya & 72.67 & 100.58 & 11 & 306 & 1.97 & 2.61 & 8.76 & 136.57 \\
\hline Mullaitivu & 22.33 & 23.80 & 1 & 72 & 1.14 & 0.10 & 7.21 & 37.46 \\
\hline Batticaloa & 237.33 & 274.23 & 66 & 1020 & 2.54 & 6.66 & 63.10 & 411.57 \\
\hline Ampara & 32.33 & 20.19 & 11 & 81 & 1.51 & 2.25 & 19.50 & 45.16 \\
\hline Trincomalee & 247.42 & 375.07 & 45 & 1366 & 2.87 & 8.53 & 9.11 & 485.72 \\
\hline Kurunegala & 268.17 & 184.36 & 119 & 655 & 1.50 & 1.17 & 151.03 & 385.30 \\
\hline Puttalam & 188.08 & 194.83 & 29 & 624 & 1.47 & 1.10 & 64.29 & 311.87 \\
\hline Anuradhapura & 97.00 & 80.31 & 34 & 270 & 1.73 & 1.83 & 45.97 & 148.03 \\
\hline Polonnaruwa & 46.75 & 30.32 & 19 & 108 & 1.51 & 1.35 & 27.49 & 66.01 \\
\hline Badulla & 160.17 & 148.57 & 41 & 490 & 1.63 & 1.58 & 65.77 & 254.56 \\
\hline Moneragala & 27.75 & 24.26 & 0 & 60 & -0.04 & -1.81 & 12.34 & 43.16 \\
\hline Ratnapura & 340.50 & 156.31 & 165 & 687 & 0.79 & 0.61 & 241.18 & 439.82 \\
\hline Kegalle & 226.33 & 128.83 & 90 & 494 & 0.80 & -0.18 & 144.48 & 308.19 \\
\hline Kalmunai & 127.42 & 149.01 & 29 & 497 & 2.01 & 3.19 & 32.74 & 222.09 \\
\hline
\end{tabular}

It has been observed that humidity and temperature consistently significantly correlated with the number of Aedes contagions in all individual years. It can be said that the spread of infection increases with the increase in humidity in Sri Lanka.

Table 3 elucidates that air pressure had a significant negative correlation with dengue transmission. It has been observed that both Kendall's tau_ $b$ and Spearman's rho correlation coefficient show consistent results from year to year. The non-parametric Kruskal-Wallis $H$ test found that climate season, bioclimatic zone, and nominal years were significant with the spread of dengue infection, indicating a significant mean difference in dengue infection among the categories of the seasonal, spatial, and temporal

Table 3 Correlation between the spread of Aedes infections and environmental factors in individual years

\begin{tabular}{|c|c|c|c|c|c|c|c|c|c|c|}
\hline \multirow[t]{2}{*}{ Environmental factors } & \multicolumn{2}{|l|}{2015} & \multicolumn{2}{|l|}{2016} & \multicolumn{2}{|l|}{2017} & \multicolumn{2}{|l|}{2018} & \multicolumn{2}{|l|}{2019} \\
\hline & Kendall & Spearman & Kendall & Spearman & Kendall & Spearman & Kendall & Spearman & Kendall & Spearman \\
\hline Precipitation (mm) & 0.03 & 0.03 & 0.02 & 0.02 & 0.01 & 0.03 & 0.05 & 0.05 & $.28 * *$ & $.41 * *$ \\
\hline Humidity (\%) & $.14 * *$ & $.21 * *$ & $.25 * *$ & $.38 * *$ & $.16^{* *}$ & $.25 * *$ & $.16^{* *}$ & $.24 * *$ & $.33 * *$ & $.48 * *$ \\
\hline Air pressure $(\mathrm{kPa})$ & $-.08 *$ & $-.13 *$ & $-.23 * *$ & $-.34 * *$ & $-.17 * *$ & $-.25^{* *}$ & $-.09 * *$ & $-.15^{* *}$ & -0.053 & -0.08 \\
\hline Temperature $\left({ }^{\circ} \mathrm{C}\right)$ & $-.18 * *$ & $-.27 * *$ & $-.28 * *$ & $-.42 * *$ & $-.09 *$ & $-.15^{* *}$ & $-.13^{* *}$ & $-.19 * *$ & $-.23 * *$ & $-.34 * *$ \\
\hline Wind speed $(\mathrm{m} / \mathrm{s})$ & -0.04 & -0.05 & $.11 * *$ & $.17 * *$ & $.12 * *$ & $.18 * *$ & 0.05 & 0.07 & -0.04 & -0.06 \\
\hline Sky clearness & $.21 * *$ & $.28 * *$ & $.14 * *$ & $.20 * *$ & $.17 * *$ & $.22 * *$ & 0.001 & 0.003 & $-.25 * *$ & $-.37 * *$ \\
\hline
\end{tabular}

$* * p<0.01$ (2-tailed); $* p<0.05$ (2-tailed) 
variables. Besides the bivariate analysis for individual years, it was also performed for the aggregate dataset of the year 2015-2019 and illustrated in Table 4.

The results in Table 4 illustrate that precipitation $(r=0.05, p<0.05)$ and humidity $(r=0.11, p<0.05)$ were positively significantly correlated with dengue transmission. The results also revealed temperature $(r=-0.14, p<0.05)$ and air pressure $(r=-0.13, p<0.05)$ had significant negative relationships with the spread of dengue. Wind speed $(r=0.06, p<0.05)$ was found to have a substantial positive correlation with dengue infection, while sky clearness $(r=0.014, p>0.05)$ was insignificant. This study found a significant negative correlation between temperature and the spread of Aedes infection $(r=-0.139, p<0.05)$. Previous studies investigated the impact of different climatic features and found monthly rainfall, number of rainy days, relative

Table 4 Correlation between the spread of dengue infections and environmental factors (2015-2019)

\begin{tabular}{|c|c|c|c|c|}
\hline \multirow{3}{*}{$\begin{array}{l}\text { Environmental } \\
\text { factors }\end{array}$} & \multicolumn{2}{|l|}{ Kendall's tau_ $b$} & \multicolumn{2}{|l|}{ Spearman's rho } \\
\hline & \multicolumn{2}{|c|}{ No. of dengue infection } & \multicolumn{2}{|c|}{ No. of dengue infection } \\
\hline & Corr.coeff. $(r)$ & $p$ value & Corr.coeff. $(r)$ & $p$ value \\
\hline Precipitation (mm) & .050 & 0.003 & .074 & 0.004 \\
\hline Humidity (\%) & .108 & 0.000 & .163 & 0.000 \\
\hline Pressure $(\mathrm{kPa})$ & -.128 & 0.000 & -.194 & 0.000 \\
\hline Temperature $\left({ }^{\circ} \mathrm{C}\right)$ & -.139 & 0.000 & -.212 & 0.000 \\
\hline Wind speed $(\mathrm{m} / \mathrm{s})$ & .060 & 0.000 & .089 & 0.000 \\
\hline Sky clearness & 0.014 & 0.446 & 0.019 & 0.457 \\
\hline
\end{tabular}

humidity, and minimum temperature have shown significant correlations with the disease in Sri Lanka (Withanage et al. 2018). Similarly, average temperature, humidity, and low to medium rainfall were found significantly associated with the dengue incidence in Bangladesh (Mutsuddy et al. 2019). A diagram of the monthly average of different environmental factors and dengue cases in 2019 is demonstrated in Fig. 4 to visually identify the relative impact of meteorological factors on the spread of dengue disease.

A positive relationship is observed between precipitation and relative humidity with the dengue infection. Figure $4 \mathrm{a}$ and $4 \mathrm{~b}$ illustrates that cases increase with increased rainfall and humidity. Similar to this study, research revealed that the number of dengue infections increases with the increase in precipitation and humidity. (Liyanage et al. 2016b; Sirisena et al. 2017). Moreover, Fig. 4c, d is shown that sky clearness and temperature negatively affected the spread of infection. Furthermore, Fig. 4e, f depicted air pressure and wind speed did not affect the spread of dengue infection during 2019 in Sri Lanka. A study suggested that the dengue fever incidence was significantly related to temperature, rainfall, and sunshine (Lai 2018).

In this study, the influential factors that significantly impact the study variable were also determined by employing a generalized linear model. Table 5 compares the NBR model with $\log$ link results along with regression coefficients and odds ratios in different years, identifying the impact of meteorological, seasonal, and spatial factors on the spread of Aedes infection in Sri Lanka. The variable sky clearness was not included in the models as it was not significant in the
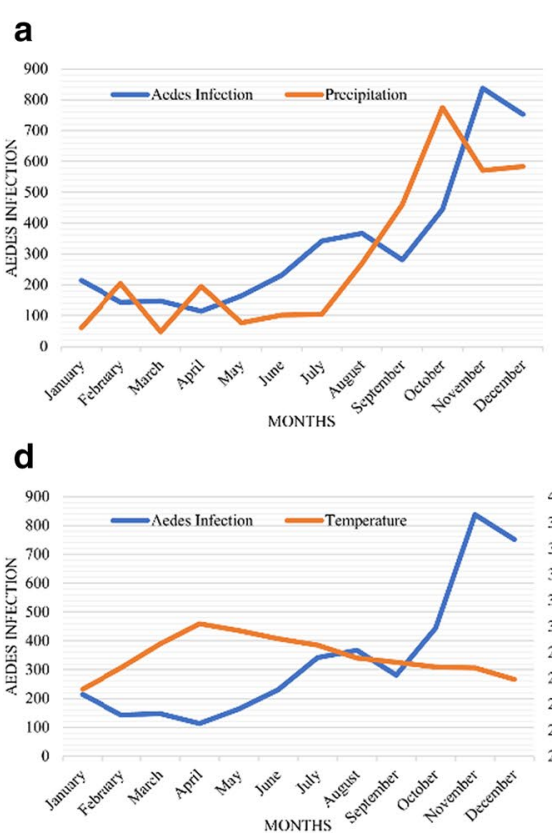

\section{b}
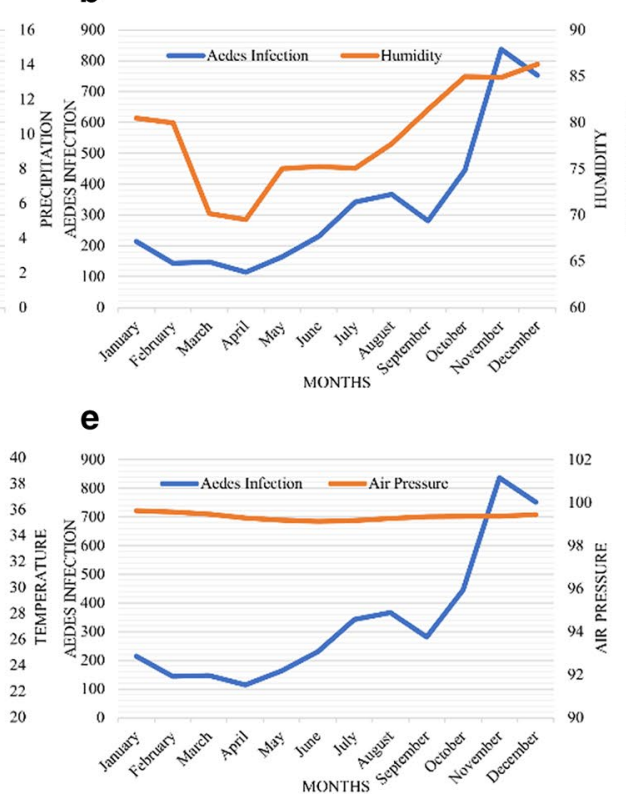
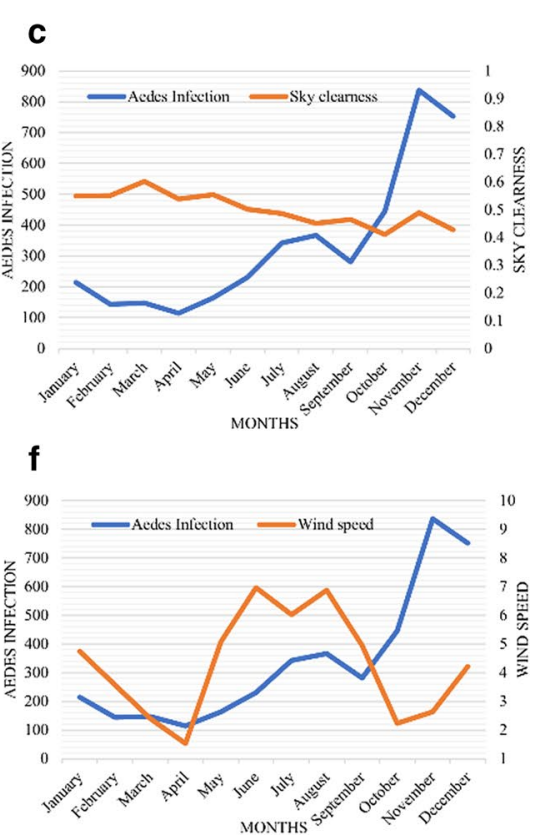

Fig. 4 Monthly average of dengue cases with the average of environmental factors in 2019 
Table 5 Temporal comparison of the impact of spatial, seasonal, and meteorological factors on the spread of dengue fever in Sri Lanka (negative binomial regression with log link)

\begin{tabular}{|c|c|c|c|c|c|c|c|c|c|c|}
\hline \multirow[t]{2}{*}{ Environmental factors } & \multicolumn{2}{|l|}{2015} & \multicolumn{2}{|l|}{2016} & \multicolumn{2}{|l|}{2017} & \multicolumn{2}{|l|}{2018} & \multicolumn{2}{|l|}{2019} \\
\hline & $B$ & $E(B)$ & $B$ & $E(B)$ & $B$ & $E(B)$ & $B$ & $E(B)$ & $B$ & $E(B)$ \\
\hline Intercept & -50.9 & $0.00 * *$ & -38.6 & $0.00 * *$ & -37.3 & $0.00^{* *}$ & -45.3 & $0.00 * *$ & -17.5 & $0.00 * *$ \\
\hline Precipitation(mm) & -0.09 & $0.91 * *$ & -0.08 & $0.92 * *$ & -0.08 & $0.92 * *$ & -0.04 & 0.96 & 0.07 & $1.07 * *$ \\
\hline Humidity (\%) & 0.05 & 1.06 & 0.03 & 1.03 & 0.04 & 1.04 & 0.04 & $1.05 * *$ & 0.03 & 1.03 \\
\hline Air pressure $(\mathrm{kPa})$ & 0.50 & $1.65^{* *}$ & 0.39 & $1.48 * *$ & 0.40 & $1.50 * *$ & 0.48 & $1.61 * *$ & 0.18 & $1.20 *$ \\
\hline Temperature $\left({ }^{\circ} \mathrm{C}\right)$ & 0.01 & 1.01 & 0.01 & 1.01 & 0.00 & 1.00 & -0.05 & 0.95 & 0.02 & 1.02 \\
\hline Wind speed $(\mathrm{m} / \mathrm{s})$ & -0.02 & 0.98 & -0.02 & 0.98 & 0.13 & $1.14 * *$ & 0.00 & 1.00 & 0.22 & $1.24 * *$ \\
\hline Zone (Intermediate) & 1.74 & $5.68 * *$ & 2.21 & $9.07 * *$ & 1.91 & $6.77 * *$ & 1.49 & $4.45 * *$ & 1.44 & $4.21^{* *}$ \\
\hline Zone (Wet) & 2.30 & $9.99 * *$ & 2.35 & $10.4 * *$ & 1.84 & $6.30 * *$ & 1.45 & $4.26 * *$ & 1.82 & $6.15^{* *}$ \\
\hline Season (NEM) & 0.77 & $2.16^{* *}$ & 0.71 & $2.04 * *$ & -0.49 & 0.61 & 0.17 & 1.19 & -0.10 & 0.91 \\
\hline Season (SIM) & 0.74 & $2.09 * *$ & 0.60 & $1.83 * *$ & -0.32 & 0.72 & -0.32 & 0.73 & 0.35 & 1.43 \\
\hline Season (SWM) & -0.35 & 0.71 & 0.06 & 1.06 & -0.05 & 0.95 & 0.06 & 1.06 & -0.78 & 0.46 \\
\hline AIC (NBR) & 3186.801 & & 3530.12 & & 4394.15 & & 3695.06 & & 3989.47 & \\
\hline $\mathrm{AIC}(\mathrm{PR})$ & $30,713.218$ & & $51,309.728$ & & $138,908.826$ & & $46,171.067$ & & $103,243.185$ & \\
\hline
\end{tabular}

$* * p<0.01, * p<0.05, B$ is the regression coefficient, $E(B)$ is the odds ratio

aggregate bivariate analysis. The table shows that precipitation, air pressure, and climatic zone significantly impact dengue transmission almost every year. Wind speed was found to have a substantial influence in 2017 and 2019.

Negative binomial regression revealed a substantial effect of climate season on dengue infection in 2015 and 2016 but was not significant for the remaining years. The AIC values in Table 5 were least for NBR models than PR models, indicating the NBR model best fit the data than the PR model.

Like the regression analysis for single years, the overdispersed count data regression model was also applied for the aggregate dataset (2015-2019). The AIC value of the NBR aggregate model (AIC: 19587.67) was less than the PR model (AIC: 625303.13), indicating that the NBR model is appropriate for the current study. In the aggregate model, a new explanatory variable, "year," was introduced to investigate the yearly nominal risk of the spread of dengue infection and is presented in Table 6. The variable "year" was found significant with dengue infection in Sri Lanka, and the odds ratio was found $8.04(p<0.01)$ for the year 2017 , indicating that the risk of dengue infection was 8.04 times higher in 2017 compared to 2015. The odds ratio for 2019 was 4.09 (95\% CI 3.25-5.15, $p<0.01$ ), approximately half of the year 2017. A study conducted in Sri Lanka supported the result of this study and disclosed that dengue infection increased significantly in 2017 compared to the preceding 5 years of surveillance (Tissera et al. 2020).

The aggregate negative binomial regression model disclosed that precipitation significantly influenced (Odds: $0.97,95 \%$ CI $0.97-0.99, p<0.05$ ) the spread of dengue fever in Sri Lanka. The odds ratio of precipitation 0.97 indicates that the risk of spreading dengue incidence decreased by
$3 \%$ for a one-unit increase in rainfall. A model analysis in Hong Kong found a negative relationship between rainfall and Aedes infection (Yuan et al. 2020). Moreover, heavy rainfalls create the chance of flushing or killing the immature mosquitoes and transiently reduce the infection risk, but the elevated humidity increases mosquito survival (Sarfraz et al. 2012). In contrast, some studies found that one extra rainy day in a month causes the increase in dengue cases by $6 \%$ in the following month (Rahman et al. 2020). Humidity (Odds: $1.05,95 \%$ CI 1.04-1.07, $p<0.01$ ) and air pressure (Odds: $1.46,95 \%$ CI 1.36-1.56, $p<0.01$ ) had substantial impacts on the dengue fever transmission. The odds ratio of humidity 1.05 indicates that for a one-unit increase in humidity, the risk of dengue infection also increases by 1.05 times. Similarly, the odds ratio of 1.46 for air pressure means for a $1 \mathrm{kPa}$ increase in air pressure, the odds of dengue incidence would be 1.46 times more. A similar study supported our result, which found that relative humidity was significantly positively related to the increase in dengue incidence (Karim et al. 2012). Increased rainfall and relative humidity strongly affected Malaysia's dengue transmission (Ismail et al. 2010). Multivariate analysis did not show any significant impact of temperature on the spread of dengue infection. Similar to our findings, the literature found that temperature is not a significant factor and even had no immediate effect on dengue incidence (Sirisena et al. 2017; Santos et al. 2019). The relation between temperature and infection was insignificant in the capital city Colombo, located in the wet region (Prabodanie et al. 2020a). However, different studies revealed diverse conclusions regarding the effect of temperature on vector breeding and dengue infection rate. The recent literature stated that an increase 
Table 6 Impact of spatial, seasonal, and environmental factors on the transmission of dengue infection in Sri Lanka (2015-2019)

\begin{tabular}{|c|c|c|c|c|c|c|c|}
\hline \multirow[t]{2}{*}{ Environmental factors } & \multirow[t]{2}{*}{ Coefficient } & \multirow[t]{2}{*}{ Standard error } & \multirow[t]{2}{*}{$Z$-value } & \multirow[t]{2}{*}{ Odds ratio } & \multicolumn{3}{|c|}{ 95\% Confidence interval (OR) } \\
\hline & & & & & Lower limit & Upper limit & $p$ value \\
\hline Intercept & -38.85 & 2.40 & -16.20 & 0.00 & 0.00 & 0.00 & 0.000 \\
\hline Precipitation (mm) & -0.03 & 0.01 & -2.76 & 0.97 & 0.95 & 0.99 & 0.006 \\
\hline Humidity (\%) & 0.05 & 0.01 & 6.47 & 1.05 & 1.04 & 1.07 & 0.000 \\
\hline Air pressure $(\mathrm{kPa})$ & 0.38 & 0.03 & 12.41 & 1.46 & 1.36 & 1.56 & 0.000 \\
\hline Temperature $\left({ }^{\circ} \mathrm{C}\right)$ & 0.01 & 0.04 & 0.25 & 1.01 & 0.94 & 1.09 & 0.805 \\
\hline Wind speed $(\mathrm{m} / \mathrm{s})$ & 0.06 & 0.02 & 2.78 & 1.06 & 1.02 & 1.11 & 0.005 \\
\hline Zone (Intermediate) & 1.76 & 0.09 & 19.11 & 5.78 & 4.67 & 7.16 & 0.000 \\
\hline Zone (Wet) & 1.86 & 0.08 & 24.53 & 6.41 & 5.49 & 7.50 & 0.000 \\
\hline Season (NEM) & 0.38 & 0.12 & 3.21 & 1.46 & 1.15 & 1.84 & 0.001 \\
\hline Season (SIM) & 0.14 & 0.11 & 1.31 & 1.16 & 0.92 & 1.45 & 0.191 \\
\hline Season (SWM) & 0.01 & 0.09 & 0.10 & 1.01 & 0.85 & 1.20 & 0.920 \\
\hline Year (2016) & 0.62 & 0.09 & 6.98 & 1.85 & 1.56 & 2.21 & 0.000 \\
\hline Year (2017) & 2.13 & 0.09 & 24.83 & 8.40 & 7.07 & 9.98 & 0.000 \\
\hline Year (2018) & 0.80 & 0.08 & 9.60 & 2.23 & 1.89 & 2.63 & 0.000 \\
\hline Year (2019) & 1.41 & 0.12 & 11.88 & 4.09 & 3.25 & 5.15 & 0.000 \\
\hline
\end{tabular}

in temperature could lead to the rapid development of the Aedes mosquitoes and increase subsequent dengue infections (Awang and Dom 2020). More precisely, a study in Thailand stated the rapid growth but lower survival rate of Aedes albopictus at higher temperatures (Phanitchat et al. 2017). Another study proved that a high-temperature condition with low fluctuation could raise the dengue cases in the next month (Sharmin et al. 2015). Moreover, the high instability of warmer temperatures has reduced the transmission (Carrington et al. 2013; Liu-Helmersson et al. 2014). This study revealed that wind speed (Odds: $1.06,95 \%$ CI $1.02-1.11, p<0.01)$ significantly impacted the spread of dengue infection, but negative impacts were found in the years 2015 and 216. The literature supported the finding, which showed that the average wind speed has a significant negative correlation in Sri Lanka (Prabodanie et al. 2020a). A study revealed that Aedes infection decreased with the increased wind speed (Yin et al. 2019).

The results of this study revealed that the factor "bioclimatic zone" constantly substantially impacted the dengue fever transmission each year. Among the three bioclimatic zones, the intermediate zone (Odds: 5.78, 95\% CI 4.67-7.16, $p<0.01$ ) had a 5.78 times more significant risk of infection than the dry zone. Moreover, the wet zone (Odds: $6.41,95 \%$ CI 5.49-7.50, $p<0.01)$ was 6.41 times more likely to be dengue infected than the dry zone. A previous study in Sri Lanka found that the wet zone and the surrounding areas contribute to the epidemic wave in the southwestern monsoon (June-August) (Prabodanie et al. 2020b). A study in Puerto Rico found that the associations between climate factors and dengue infection were varied spatially (Johansson et al. 2009). A study reviewed the full text of 128 articles and observed that the arboviral epidemic depends on the climate zones (Liu et al. 2020).

Analyses showed that the climate season of Sri Lanka also had a significant impact on the spread of dengue infection. Among all the seasons, the NEM season (Odds: 1.46, 95\% CI 1.15-1.84, $p<0.01)$ significantly influenced the increase in dengue infection in Sri Lanka. Our result was concordant with a similar study which also found that the two dengue epidemics in Sri Lanka have occurred in southwestern monsoon from May to September and north-eastern monsoon from December to January (Sirisena and Noordeen 2014; Sun et al. 2017). A study of the seasonal variation on dengue transmission prediction in Thailand revealed that seasonal variation significantly impacted dengue incidence, and more Aedes larvae were observed in the rainy season than in the winter and summer season (Wongkoon et al. 2013).

From the discussions mentioned above, it can be concluded that precipitation negatively impacts the spread of Aedes contagions, and increasing rainfall causes the decrease of the disease. On the other hand, humidity and air pressure positively influence dengue fever. Growing humidity, air pressure, and wind speed increase the dengue illness. Bioclimatic zones substantially influence the spread of the infection, and the wet and intermediate zones were found more vulnerable to dengue disease than the dry zone. Moreover, the wet zone had the highest risk of spreading the disease among all other zones. Furthermore, the northeast monsoon season significantly impacted the Aedes infection in Sri Lanka, and in this season, the jeopardy of dengue disease was higher than in all other seasons. The risk of dengue infection was significantly higher 
in 2017 than in other years. The precipitation, air pressure, wind speed, and bioclimatic zone greatly impacted the outbreak in 2017 , and the people who stayed in the wet zone were more vulnerable to this disease in the same year. Despite the meteorological features, the dengue vector's spread may be influenced by other socio-economic, demographic, and geographical factors such as population density, drainage system, disposal waste management which were not considered in the current research. This study intensively investigated the meteorological factors by applying the more appropriate statistical methods. Therefore, the obtained results will help local authorities to take the necessary steps for dengue prevention based on the climatic condition of the study area.

\section{Conclusion}

Dengue is a mosquito-borne flu-like illness that causes severe health problems and is found as endemic in many countries. This study determines the essential environmental factors affecting dengue disease in Sri Lanka. This research also identifies the most at-risk bioclimatic zones and climate seasons using the most appropriate statistical methods based on the secondary data from January 2015 to December 2019 in Sri Lanka. Precipitation and air pressure had a significant effect on the spread of dengue fever each year. In addition to precipitation and air pressure, wind speed and bioclimatic zone are identified as the main influential factors for the dengue outbreak in 2017. The aggregate NBR model reveals that precipitation, air pressure, humidity, wind speed, bioclimatic zone, seasonal variation, and the nominal year significantly impacted the spread of dengue fever. The wet zone had a significant impact on the vast Aedes infection. The Northeast monsoon season greatly influenced the spread of dengue disease in Sri Lanka. Moreover, future research, including population density and mobility, health care system, drainage facility, disposal waste management, etc., should be done to identify the substantial reasons for dengue transmission. The study results indeed contribute to combating the enormous spread of dengue infection in the local as well as other tropical and subtropical areas in the world. These findings will help policymakers to take the necessary steps for dengue prevention based on the country's seasonal climate variability in different geographic regions.

Acknowledgements We are grateful to the Health Ministry of Sri Lanka for providing dengue infection data on their website. We are also thankful to the NASA Power Access Data website for its openaccess environmental data repository and availability.

Funding This research did not receive any specific grant from funding agencies in public, commercial, or not-for-profit sectors.
Availability of data Supplementary data related to this article are publicly available on https://data.mendeley.com/datasets/z94mj5znhj/ draft?a=2557ceb5-01b7-466c-bbb8-60c30498beb5.

Code availability The code for this research will be provided on request.

\section{Declarations}

Conflict of interest The author declares that they do not have any conflict of interest.

Ethical approval This article does not contain any studies with human participants or animals performed by any of the authors.

\section{References}

Asian Disaster Reduction Center (2020) SRI LANKA

Awang MF, Dom NC (2020) The effect of temperature on the development of immature stages of Aedes spp. against breeding containers. Int J Glob Warm 21:215-233. https://doi.org/10.1504/IJGW. 2020.108671

Bhatt S, Gething PW, Brady OJ et al (2013) The global distribution and burden of dengue. Nat 4967446(496):504-507. https://doi. org/10.1038/nature12060

Blanford JI, Blanford S, Crane RG et al (2013) Implications of temperature variation for malaria parasite development across Africa. Sci Rep 3:1-11. https://doi.org/10.1038/srep01300

Brady OJ, Golding N, Pigott DM et al (2014) Global temperature constraints on Aedes aegypti and Ae. albopictus persistence and competence for dengue virus transmission. Parasites Vectors 71(7):1-17. https://doi.org/10.1186/1756-3305-7-338

Carrington LB, Armijos MV, Lambrechts L, Scott TW (2013) Fluctuations at a low mean temperature accelerate dengue virus transmission by Aedes aegypti. PLoS Negl Trop Dis 7:e2190. https://doi. org/10.1371/journal.pntd.0002190

Choi Y, Tang CS, McIver L et al (2016) Effects of weather factors on dengue fever incidence and implications for interventions in Cambodia. BMC Public Health 161(16):1-7. https://doi.org/10. 1186/S12889-016-2923-2

Climate of Sri Lanka [WWW Document] (2021) URL http://www. meteo.gov.lk/index.php?option $=$ com_content $\&$ view $=$ article $\&$ id $=94 \&$ Itemid $=310 \&$ lang=en\&lang $=$ en. Accessed 10 Jan 2021

Daily News (2017) Nearly 400 dengue deaths so far this yearlDaily News. http://www.dailynews.lk/2017/09/19/local/128567/nearly400-dengue-deaths-so-far-year. Accessed 6 Jul 2021

Department of meteorology (2019) Climate of Sri Lanka. http://www. meteo.gov.lk/index.php?option $=$ com_content $\&$ view $=$ article $\&$ $\mathrm{id}=94 \&$ Itemid=310\&lang=en\&lang=en. Accessed 10 Jun 2021

Epidemiology Unit of Ministry of Health (2019) Dengue cases by month in Sri Lanka. http://www.epid.gov.lk/web/index.php? Itemid $=448 \&$ lang $=$ en\&option $=$ com_casesanddeaths. Accessed 4 Jul 2021

HOMER Calculates Clearness Index. In: 2021. https://www.homer energy.com/products/pro/docs/latest/how_homer_calculates_clear ness index.html. Accessed 4 Jul 2021

Ismail S, Samah AA, Sulaiman WYW, Shafie A (2010) Ismail: Influence of the environment and climate... - Google Scholar. of the environment and climate towards the spread of dengue epidemic in Kuala Lumpur 2008\%3A An Initial Finding. Proceedings of the first national symposium on resilience $\% 2 \mathrm{C}$ vulnerability and 
adaptation to the climate change https://scholar.google.com/schol ar_lookup?title=Influencethreat $\% 2 \mathrm{Cmalaysia \& publication \_ year=}$ 2010\&author $=$ SIsmail \&author $=$ AASamah\&author $=$ WYWSu laiman\&author=AShafie. Accessed 5 Jul 2021

Johansson MA, Dominici F, Glass GE (2009) Local and global effects of climate on dengue transmission in Puerto Rico. PLoS Negl Trop Dis 3:e382. https://doi.org/10.1371/JOURNAL.PNTD. 0000382

Johansson MA, Reich NG, Hota A et al (2016) Evaluating the performance of infectious disease forecasts: a comparison of climate-driven and seasonal dengue forecasts for Mexico. Sci Rep 61(6):1-11. https://doi.org/10.1038/srep33707

Karim MN, Munshi SU, Anwar N, Alam MS (2012) Climatic factors influencing dengue cases in Dhaka city: a model for dengue prediction. Indian J Med Res 136:32-39. https://doi.org/10.1016/j. ijid.2018.04.3862

Lai YH (2018) The climatic factors affecting dengue fever outbreaks in southern Taiwan: an application of symbolic data analysis. Biomed Eng Online. https://doi.org/10.1186/S12938-018-0575-4

Lazarus NW (2021) Multivariate analysis of the dengue virus in Sri Lanka using the ordination method. GeoJournal 86:281-302. https://doi.org/10.1007/s10708-019-10069-3

Liu Y, Lillepold K, Semenza JC et al (2020) Reviewing estimates of the basic reproduction number for dengue, Zika and chikungunya across global climate zones. Environ Res 182:109114. https://doi. org/10.1016/J.ENVRES.2020.109114

Liu-Helmersson J, Stenlund H, Wilder-Smith A, Rocklöv J (2014) Vectorial capacity of Aedes aegypti: effects of temperature and implications for global dengue epidemic potential. PLoS ONE 9:e89783. https://doi.org/10.1371/journal.pone.0089783

Liyanage $\mathrm{P}$, Tissera $\mathrm{H}$, Sewe $\mathrm{M}$ et al (2016a) A spatial hierarchical analysis of the temporal influences of the el niño-southern oscillation and weather on dengue in Kalutara District, Sri Lanka. Int J Environ Res Public Health. https://doi.org/10.3390/ijerph1311 1087

Liyanage P, Tissera H, Sewe M et al (2016b) A spatial hierarchical analysis of the temporal influences of the El Niño-southern oscillation and weather on dengue in Kalutara District, Sri Lanka. Int J Environ Res Public Health 13:1087. https://doi.org/10.3390/ IJERPH13111087

Messina JP, Brady OJ, Golding N et al (2019) The current and future global distribution and population at risk of dengue. Nat Microbiol 49(4):1508-1515. https://doi.org/10.1038/s41564-019-0476-8

Mordecai EA, Cohen JM, Evans MV et al (2017) Detecting the impact of temperature on transmission of Zika, dengue, and chikungunya using mechanistic models. PLoS Negl Trop Dis 11:e0005568. https://doi.org/10.1371/JOURNAL.PNTD.0005568

Mustafa MS, Rasotgi V, Jain S, Gupta V (2015) Discovery of fifth serotype of dengue virus (DENV-5): a new public health dilemma in dengue control. Med J Armed Forces India 71:67-70. https:// doi.org/10.1016/J.MJAFI.2014.09.011

Mutsuddy P, Tahmina Jhora S, Shamsuzzaman AKM et al (2019) Dengue situation in Bangladesh: an epidemiological shift in terms of morbidity and mortality. Can J Infect Dis Med Microbiol. https:// doi.org/10.1155/2019/3516284

Naish S, Dale P, Mackenzie JS et al (2014) Climate change and dengue: a critical and systematic review of quantitative modelling approaches. BMC Infect Dis 14:1-14. https://doi.org/10.1186/ 1471-2334-14-167

NASA Power (2021) NASA POWERIData access viewer. https://power. larc.nasa.gov/data-access-viewer/. Accessed 4 Jul 2021

Ooi E-E, Goh K-T, Gubler DJ (2006) Dengue prevention and 35 years of vector control in Singapore. Emerg Infect Dis 12:887. https:// doi.org/10.3201/10.3201/EID1206.051210

Phanitchat T, Apiwathnasorn C, Sumroiphon S, Samung Y, Naksathit A, Thawornkuno C, Sungvornyothin S et al (2017) The influence of temperature on the developmental rate and survival of Aedes albopictus in Thailand. Southeast Asia J Trop Med Public Health 48:799-808

Prabodanie RAR, Schreider S, Cazelles B, Stone L (2020a) Coherence of dengue incidence and climate in the wet and dry zones of Sri Lanka. Sci Total Environ. https://doi.org/10.1016/j.scito tenv.2020.138269

Prabodanie RAR, Stone L, Schreider S (2020b) Spatiotemporal patterns of dengue outbreaks in Sri Lanka. Infect Dis (Auckl) 52:350-360. https://doi.org/10.1080/23744235.2020.1725108

Rahman MS, Rahman T (2020) Risks of simultaneous coinfection of dengue and COVID-19 in Bangladesh: challenges and recommendations. Dr Sulaiman Al Habib Med J 2:137. https://doi.org/10. 2991/dsahmj.k.201124.001

Rahman KM, Sharker Y, Rumi RA et al (2020) An association between rainy days with clinical dengue fever in Dhaka, Bangladesh: findings from a hospital based study. Int J Environ Res Public Health 17:1-9. https://doi.org/10.3390/ijerph17249506

Rahman BMS, Mehejabin F, Rashid R (2021a) A community based case-control study to determine the risk factors of dengue fever in Bangladesh. medRxiv. https://doi.org/10.1101/2021.08.24.21262 563

Rahman MS, Faruk MO, Tanjila S et al (2021b) Entomological survey for identification of Aedes larval breeding sites and their distribution in Chattogram, Bangladesh. Beni-Suef Univ J Basic Appl Sci 10:1-11. https://doi.org/10.1186/s43088-021-00122-x

Santos CAG, Guerra-Gomes IC, Gois BM et al (2019) Correlation of dengue incidence and rainfall occurrence using wavelet transform for João Pessoa city. Sci Total Environ 647:794-805. https://doi. org/10.1016/j.scitotenv.2018.08.019

Sarfraz MS, Tripathi NK, Tipdecho T et al (2012) Analyzing the spatio-temporal relationship between dengue vector larval density and land-use using factor analysis and spatial ring mapping. BMC Public Health 121(12):1-19. https://doi.org/10.1186/ 1471-2458-12-853

Sharmin S, Glass K, Viennet E, Harley D (2015) Interaction of mean temperature and daily fluctuation influences dengue incidence in Dhaka, Bangladesh. Plos Negl Trop Dis 9:3901. https://doi.org/ 10.1371/journal.pntd.0003901

Sharmin S, Glass K, Viennet E, Harley D (2018) Geostatistical mapping of the seasonal spread of under-reported dengue cases in Bangladesh. PLoS Negl Trop Dis 12:e0006947. https://doi.org/ 10.1371/journal.pntd.0006947

Sirisena PDNN, Noordeen F (2014) Evolution of dengue in Sri Lankachanges in the virus, vector, and climate. Int J Infect Dis 19:6-12. https://doi.org/10.1016/j.ijid.2013.10.012

Sirisena P, Noordeen F, Kurukulasuriya H et al (2017) Effect of climatic factors and population density on the distribution of dengue in Sri Lanka: a GIS based evaluation for prediction of outbreaks. PLoS ONE 12:e0166806. https://doi.org/10.1371/JOURNAL. PONE.0166806

Sun W, Xue L, Xie X (2017) Spatial-temporal distribution of dengue and climate characteristics for two clusters in Sri Lanka from 2012 to 2016. Sci Rep 71(7):1-12. https://doi.org/10.1038/ s41598-017-13163-z

Tissera HA, Jayamanne BDW, Raut R et al (2020) Severe dengue epidemic, Sri Lanka, 2017. Emerg Infect Dis 26:682. https://doi.org/ 10.3201/EID2604.190435

Wagner CE, Hooshyar M, Baker RE et al (2020) Climatological, virological and sociological drivers of current and projected dengue fever outbreak dynamics in Sri Lanka. J R Soc Interface. https:// doi.org/10.1098/RSIF.2020.0075

Withanage GP, Viswakula SD, Gunawardena YINS, Hapugoda MD (2018) A forecasting model for dengue incidence in the District of Gampaha, Sri Lanka. Parasites Vectors 111(11):1-10. https:// doi.org/10.1186/S13071-018-2828-2 
Wongkoon S, Jaroensutasinee M, Jaroensutasinee K (2013) Distribution, seasonal variation \& dengue transmission prediction in Sisaket, Thailand. Indian J Med Res 138:347

World Mosquito Program (2021) DenguelWorld Mosquito Program. https://www.worldmosquitoprogram.org/en/learn/mosquitoborne-diseases/dengue. Accessed 16 Oct 2021

Yin Q, Li L, Guo X et al (2019) A field-based modeling study on ecological characterization of hourly host-seeking behavior and its associated climatic variables in Aedes albopictus. Parasites Vectors 12:1-14. https://doi.org/10.1186/S13071-019-3715-1/ FIGURES/6
Yuan H-Y, Liang J, Lin P-S et al (2020) The effects of seasonal climate variability on dengue annual incidence in Hong Kong: a modelling study. Sci Rep 101(10):1-10. https://doi.org/10.1038/ s41598-020-60309-7

Zhu G, Liu J, Tan Q, Shi B (2016) Inferring the spatio-temporal patterns of dengue transmission from surveillance data in Guangzhou, China. Plos Negl Trop Dis 10:e0004633. https://doi.org/ 10.1371/journal.pntd.0004633 